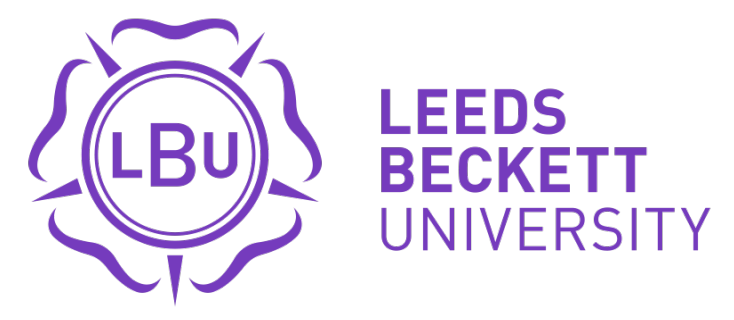

Citation:

Fletcher, MJ and Johnston, DK and Glew, D and Parker, J (2017) An empirical evaluation of temporal overheating in an assisted living Passivhaus dwelling in the UK. Building and Environment, 121. pp. 106-118. ISSN 0360-1323 DOI: https://doi.org/10.1016/j.buildenv.2017.05.024

Link to Leeds Beckett Repository record:

https://eprints.leedsbeckett.ac.uk/id/eprint/3753/

Document Version:

Article (Accepted Version)

Creative Commons: Attribution-Noncommercial-No Derivative Works 4.0

The aim of the Leeds Beckett Repository is to provide open access to our research, as required by funder policies and permitted by publishers and copyright law.

The Leeds Beckett repository holds a wide range of publications, each of which has been checked for copyright and the relevant embargo period has been applied by the Research Services team.

We operate on a standard take-down policy. If you are the author or publisher of an output and you would like it removed from the repository, please contact us and we will investigate on a case-by-case basis.

Each thesis in the repository has been cleared where necessary by the author for third party copyright. If you would like a thesis to be removed from the repository or believe there is an issue with copyright, please contact us on openaccess@leedsbeckett.ac.uk and we will investigate on a case-by-case basis. 


\title{
An empirical evaluation of temporal overheating in an assisted living Passivhaus dwelling in the UK
}

\author{
M. J. Fletcher ${ }^{1}$, D. K. Johnston ${ }^{1}$, D. W. Glew ${ }^{1}$, J. M. Parker ${ }^{1}$ \\ ${ }^{\mathbf{1}}$ Centre for the Built Environment, Leeds Sustainability Institute, Leeds Beckett University, BPA223 \\ Broadcasting Place, Woodhouse Lane, Leeds, LS2 9EN, UK
}

Corresponding Author: M.F.Fletcher@Leedsbeckett.ac.uk, +44 1138129397

Additional details: D.Johnston@Leedsbeckett.ac.uk; D.W.Glew@Leedsbeckett.ac.uk;

J.M.Parker@Leedsbeckett.ac.uk

\begin{abstract}
Global concern around energy use and anthropogenic climate change have resulted in an increased effort to reduce the energy demand and $\mathrm{CO}_{2}$ emissions attributable to buildings. This has led to the development of a number of low energy building standards, one of which is the internationally recognised Passivhaus Standard.

The Passivhaus Standard aims to reduce the space heating energy demand of a building by adopting a 'fabric first' approach, thus ensuring the thermal envelope is highly insulated and airtight whilst also maximising passive solar heat gains. However, adopting such an approach does present a risk of overheating; a situation that is of particular concern when the occupants have additional healthcare requirements.
\end{abstract}

This study uses 21 months of in-use monitored data to consider the overheating risk in a UK Passivhaus dwelling with vulnerable occupants using both static and adaptive thermal comfort assessment methods. The analysis of the data suggests the occurrence of substantial overheating according to PHPP, CIBSE Guide A and CIBSE TM52 criteria. The analysis was then expanded to consider a novel composite method to overcome the limitations of existing approaches, allowing overheating to be assessed during non-typical periods i.e. the heating 
season. This revealed apparent overheating during colder months, in addition to substantial night-time overheating. This has implications for the thermal comfort assessment of low energy dwellings and the design and operation of Passivhaus buildings, particularly those with vulnerable occupants.

\section{Keywords}

Overheating; Passivhaus; Assisted living; Thermal comfort

\section{Nomenclature}

$H_{\mathrm{e}} \quad$ Hours of exceedance

$T_{\text {comf }}$ Comfort temperature

$T_{\mathrm{db}} \quad$ Dry bulb temperature

$T_{\max } \quad$ Maximum temperature

$T_{\mathrm{MRT}} \quad$ Mean radiant temperature

$T_{\text {op }} \quad$ Operative temperature

$T_{\mathrm{rm}} \quad$ Exponentially weighted running mean outdoor temperature

$T_{\text {upp }} \quad$ Upper temperature limit

$W_{\mathrm{e}} \quad$ Weighted exceedance

$\mathrm{L}_{24} \quad$ Lounge, constant occupancy

$\mathrm{B}_{24} \quad$ Bedroom, constant occupancy

Liso Lounge, day/night occupancy profile

B ISO Bedroom, day/night occupancy profile 


\section{Introduction}

The ratification of the Paris Agreement [1] identifies that reducing carbon emissions remains a prominent global political priority. It is estimated that the built environment accounts for approximately one third of anthropogenic greenhouse gas emissions world-wide and around $40 \%$ of global energy use [2]. In the UK, the energy used in dwellings accounts for over a quarter of total energy use and carbon emissions [3]. The built environment therefore offers a significant opportunity for energy reduction, a circumstance that has led to the adoption of legislation designed to limit building energy use. For domestic dwellings in the UK, this has primarily taken the form of the Building Regulations Approved Document Part L:

Conservation of Fuel and Energy [4, 5]. In the UK, the prevailing climate conditions have resulted in an emphasis being placed on the reduction of space heating energy use. This is reflected in government policy, which has encouraged the adoption of insulation materials into the building fabric in order to reduce the associated transmission losses.

As the energy requirements for buildings have become progressively stricter, novel methods for low energy construction, which go beyond existing compliance requirements, have been developed e.g. the Passivhaus Standard. This is a voluntary standard that aims to minimise the requirement for space heating and cooling, whilst also creating high levels of indoor air quality and occupant comfort [6]. Dwellings built to the Passivhaus Standards are a relatively new concept in the UK, with the first certified Passivhaus dwelling completed in 2010 [7]. The number of UK Passivhaus certified buildings is growing, and as of January 2017 there were in excess of 500 certified units located throughout the UK, the majority of which are dwellings [8].

The standard adopts a 'fabric first' approach to the design, which requires a high performance building envelope (high levels of insulation and airtightness), the use of a mechanical 
ventilation with heat recovery (MVHR) system and the optimisation of passive solar gains. However, there is a potential risk that in designing dwellings to maximise passive gains in order to offset winter heating loads, various unintended consequences may manifest, such as an increased risk of overheating [9].

It is the ability of Passivhaus dwellings to reduce primary energy demand through passive gains that differentiates the Passivhaus Standard from more generic fabric first approaches centred around reducing heat losses, such as incorporating additional insulation products to satisfy the Standard Assessment Procedure (SAP) calculation for energy performance certification [10]. Unlike holistic approaches towards sustainability such as the Building Research Establishment Environmental Assessment Method (BREEAM) [11], Passivhaus is focussed on the reduction of primary energy demand for heating. Additionally, Passivhaus differs from net-zero energy or energy plus approaches as there is no requirement for renewable energy generation.

In recent years, a growing body of evidence has emerged that suggests that summertime overheating is becoming a significant problem in both new and existing dwellings in the UK under existing climatic conditions [9, 12-20]. Although few in number, there are some in-use performance studies for Passivhaus dwellings in the UK including the Camden Passivhaus [21], the Larch and Lime house [22, 23] and a number of flats located in the Sampson Close development in Coventry [20] indicate that summertime overheating is occurring. Elsewhere in Europe overheating in Passivhaus dwellings is recorded to be more widespread [24-29].

These findings appear to be at odds with the Passivhaus claim of superior levels of comfort to traditional buildings [30]. In addition, these assertions are likely to be of particular concern where Passivhaus design has been encouraged for dwellings that require enhanced internal conditions, such as in assisted living and healthcare. Overheating in dwellings with 
vulnerable occupants presents additional challenges [31, 32], however there is a current lack of empirical evidence for such application of Passivhaus design.

On average people spend over $85 \%$ of their time indoors [33], a figure which rises to $95 \%$ for the elderly [34]. Consequently, the provision of suitable internal conditions takes on additional significance for assisted living dwellings. Elderly people are physiologically less able to regulate their body temperature to respond to both hot and cold environments $[35,36]$, predominantly relying on adaptive strategies such as window opening and clothing modification to regulate comfort $[37,38]$. This presents a challenge for elderly residents in Passivhaus dwellings, as age-related health conditions may limit the cognitive or physical ability to understand and operate the systems for combatting overheating [39, 40].

Additionally, evidence shows that elderly people prefer a slightly warmer environment [41], particularly in cooler climatic zones [42], and are more sensitive to shifting thermal conditions $[35,41]$. This preference for warmer temperatures combined with poor thermal risk perception [40] may result in unintentional exposure to potentially harmful temperatures.

There is, however, some evidence that suggests summertime overheating can be avoided in Passivhaus buildings. For instance, the CEPHEUS (Cost Efficient Passive Houses as European Standards) project, which monitored 221 dwellings in 5 European countries, revealed that mean indoor temperatures could be kept within a comfortable range in the summer, and comfort could be improved through appropriate occupant ventilation behaviour $[6,43,44]$. It is worth noting that the aforementioned research was conducted by practitioners from the Passivhaus Institute with a detailed understanding PassivHaus dwelling operation.

Although the majority of the available literature on dwellings currently focusses on overheating in summer, evidence is also beginning to emerge that suggests that overheating can also occur within both Passivhaus and similar prototype zero carbon dwellings at other 
times of the year $[14,30]$. This suggests that the other studies may be underestimating the risks. In addition, other studies tend to use aggregate analysis methods, which identify the occurrence of overheating based on the ability to fulfil limiting criteria over a summertime period. One such method is the adaptive comfort methodology [45]. By utilising such aggregate methods, it is not possible to differentiate between daytime and night-time periods beyond the application of occupancy hours which limit the analysis of different dwelling zones to specific time periods.

The research presented in this paper presents the findings obtained from undertaking a detailed assessment of the overheating risk associated with a recently constructed Passivhaus certified dwelling throughout the entire year, i.e. presenting a seasonal temporal overheating risk assessment. In addition, it also investigates the overheating risk during the day and night, i.e. the daily temporal risks. In doing so, it will identify whether temporal overheating analysis is capable of providing a much greater depth of description and more beneficial understanding of the overheating risk than would otherwise be provided by undertaking a more common aggregate seasonal assessment method.

This research adds to the limited empirical evidence base associated with Passivhaus dwellings, and since the case study dwelling is used for assisted living accommodation, it also comments on the appropriateness of Passivhaus buildings for residents with additional healthcare requirements. The research was undertaken for 21 months and included in-use monitoring of environmental conditions as well as occupant surveys. It investigates the risk of overheating in the case study dwelling using static methods and the CIBSE TM52 methodology [46], which is derived from the adaptive thermal comfort ISO 15251 standard [45]. In addition, it also compares the predicted overheating occurrence identified by PHPP (Passive House Planning Package) with the observed reality. In order to further explore the temporal aspects of overheating in the case study Passivhaus dwelling, specifically the 
incidence of overheating in periods not considered by current protocols and the prevalence of night-time overheating, a composite method was applied to overcome the limitations of traditional approaches, the results of which are also presented.

\section{Method}

This section outlines the salient information on the case study dwelling and its occupants and proceeds to describe the data collection techniques used. The case study dwelling is a $66 \mathrm{~m}^{2}$ two bedroom end terrace bungalow (1 of 7 in the terrace), the plan for which can be seen below in Figure 1, and has a plant room in the roof void which houses the hot water tank and MVHR system. The case study dwelling forms part of a much larger development of 28 bungalows (8 end-terrace, 17 mid-terrace and 3 detached), which were constructed in 2011 in the North of England. The case study dwelling is Passivhaus certified and Code for Sustainable Homes Level 4. The development was specifically designed for older occupants and the residents of the case study dwelling reflect this. Both residents were retired and over 65 years old; one male one female, and occupied the dwelling for most of the time due to care requirements related to decreased mobility. The case study dwelling formed part of an in-use monitoring study that was undertaken as part of the Technology Strategy Boards Building Performance Evaluation Programme (The Technology Strategy Board, 2010). Further details regarding this study can be obtained from Johnston \& Fletcher [47]. 

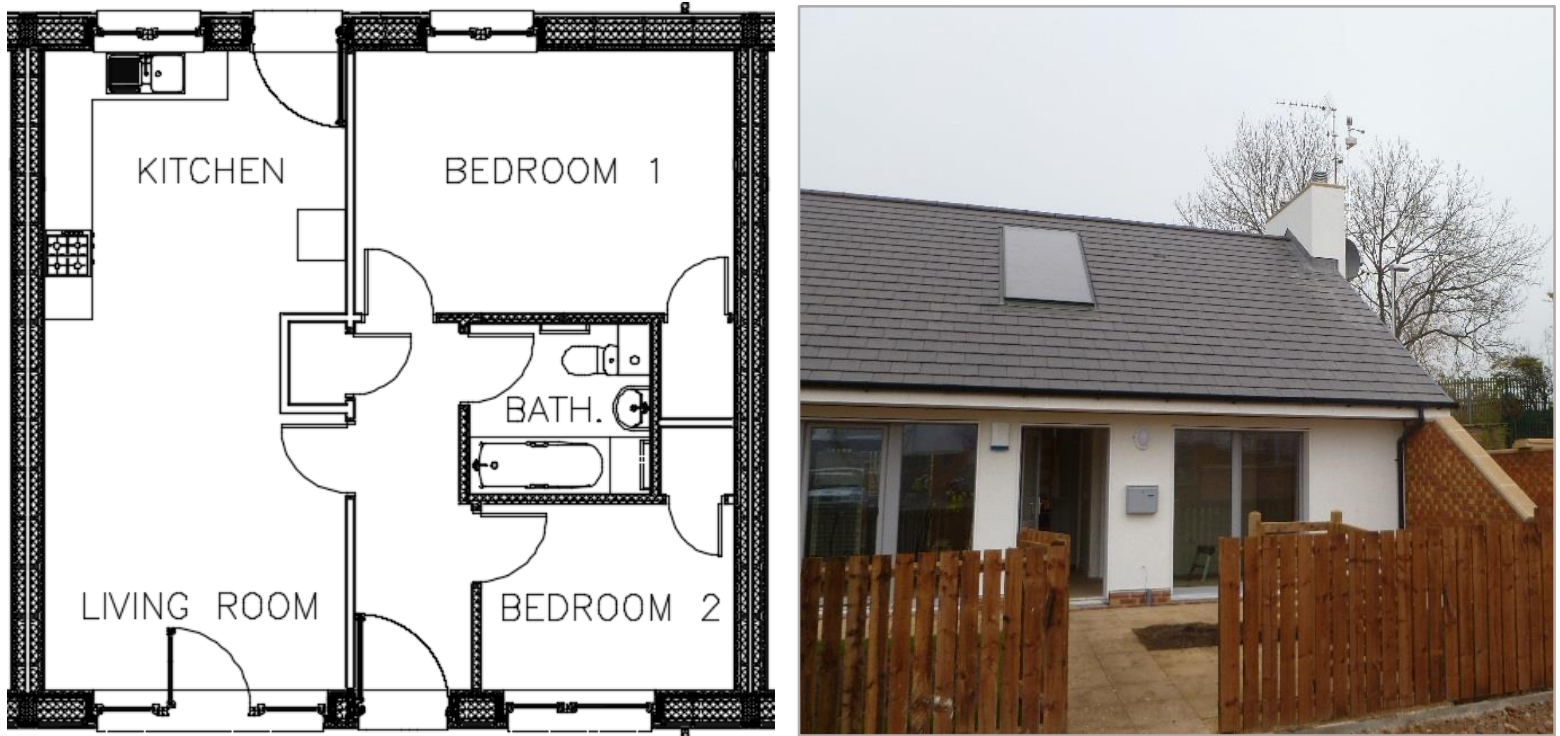

Figure 1 Floor plan and front elevation image of case study dwelling

As is illustrated in Figure 1, the case study dwelling consists of a south-facing open-plan living/kitchen area which runs the full depth of the dwelling, a north-facing master bedroom with an internal storage cupboard, a south-facing smaller bedroom with an internal storage cupboard (this cupboard also houses the main consumer unit for the dwelling) and a bathroom. Additionally, a mezzanine plant area is situated above the bathroom, corridor and both bedrooms and is only accessible via a loft hatch and ladder. It also houses the hot water tank and MVHR system and is not designed to function as a loft space.

The case study dwelling is of lightweight construction with low thermal mass (specific heat capacity of $60 \mathrm{Wh} / \mathrm{K}$ per $\mathrm{m}^{2}$ total floor area), with external walls constructed from prefabricated timber frame cassettes filled with $300 \mathrm{~mm}$ insulation and clad externally in $15 \mathrm{~mm}$ Bitroc and either brick or render. The ground floor is of reinforced concrete slab-on-ground construction, with $300 \mathrm{~mm}$ insulation and $50 \mathrm{~mm}$ screed above the slab. Windows are triple glazed low-e krypton filled units. 
Ventilation is provided by an MVHR system, with space heating provided via a small low temperature hot water heater battery installed in the MVHR ductwork. In addition to the heater battery, a heated towel radiator is provided in the bathroom, along with a small radiator in the drying cupboard. Heat provision is thermostatically controlled, with thermostat set point determined by the occupant. The dwelling has no active cooling system, with natural ventilation via window opening the primary cooling mechanism. Additionally, the MVHR system has summer bypass and boost functions to increase air exchange with the external environment. These functions are user-controlled via a control interface located in the hall. Hot water to the heater battery, towel radiator and small drying cupboard radiator are supplied from a communal boiler located in a small boiler room on the East end of the terrace. The communal boiler supplies hot water to all seven of the dwellings in the terrace via a communal heat main.

The dwelling was subjected to fabric performance testing during winter 2011 which comprised of: pressurisation testing following the method outlined in ATTMA [48]; coheating testing to the method outlined in Wingfield et al [49]; elemental effective U value assessment using the averaging method described in ISO 9869 [50] and thermographic survey for qualitative purposes. The dwelling was found to have an in situ heat loss coefficient of $46.7 \mathrm{~W} / \mathrm{K}$ with a mean air permeability of $0.89 \mathrm{~m}^{3} \cdot \mathrm{h}^{-1} \cdot \mathrm{m}^{-2} @ 50 \mathrm{~Pa}$, and as such satisfied the requirements for Passivhaus Certification.

Internal dry bulb temperature and relative humidity $(\mathrm{RH})$ data were collected from April 2013 until December 2014 using Eltek GD47 sensors with an accuracy of $\pm 0.4^{\circ} \mathrm{C}$ and $\pm 2 \%$ respectively. Sensors were located in the open plan lounge/kitchen and the master bedroom. Sensors were placed on top of storage units in order to be sensitive to occupant requests for minimal visual intrusion. Care was taken to ensure sensors were not in direct sunlight, near localised heat sources, or draughts and so were deemed representative of the room 
temperature. Due to the results of fabric performance testing, thermal stratification was assumed to satisfy the designed Passivhaus guideline of less than $2^{\circ} \mathrm{C}$ variance between ankle and head height. External environmental conditions were measured using a Vaisala WXT520 weather station, with dry bulb temperature accuracy of $\pm 0.4^{\circ} \mathrm{C}$. Data were gathered at 10 minute intervals and collected remotely using a modem.

\section{Results}

\subsection{Observed temperatures}

Thermal comfort guidance presented in CIBSE Environmental Design Guide A recommends summer temperatures between $23-25^{\circ} \mathrm{C}$ should be achieved in the living rooms and bedrooms of dwellings [51]. The distribution of monitored temperatures is shown by the box plots presented in Figure 2 and Figure 3 for the 2013 and 2014 summer period (May-September) respectively. These show the temperatures recorded during the day and night time as defined by ISO 13790 [52] guidance, which offers a representative indicator of daytime and nighttime hours; 07:00-23:00 (day) and 23:00-07:00 (night). The upper and lower thresholds are depicted for reference. As can be seen, the dwelling spends a substantial amount of time above the $25^{\circ} \mathrm{C}$ upper limit during both the day and night times in both monitored years; a minimum of $54.5 \%$ of time in 2014 . Temperatures appear higher in the Lounge, which is likely due to the internal gains from electrical appliances in this space. The data suggests internal temperatures were slightly warmer during the night in the bedroom which may be the result of reduced window opening for noise and draught attenuation in addition to increased occupancy in a smaller space. 


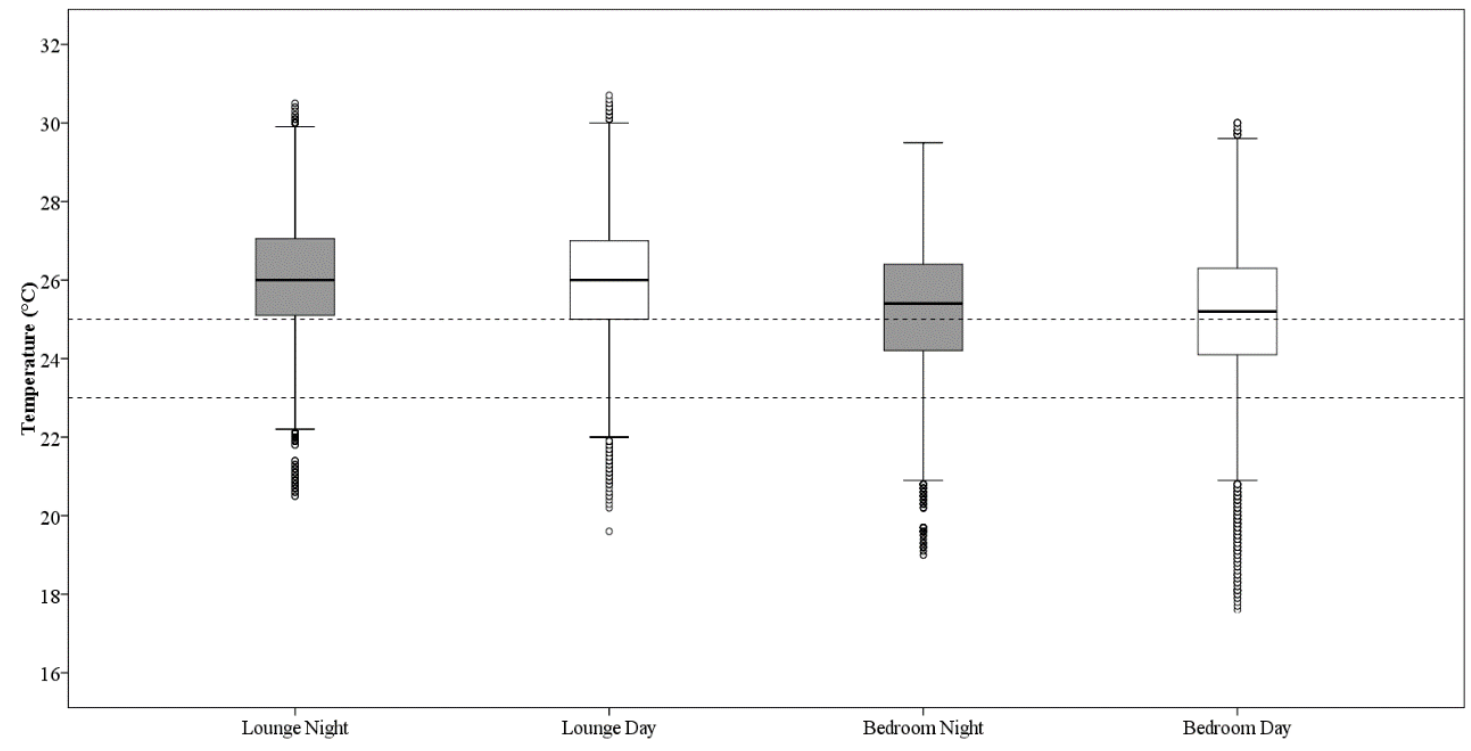

Figure 22013 temperature distribution in the lounge/kitchen area and bedroom.

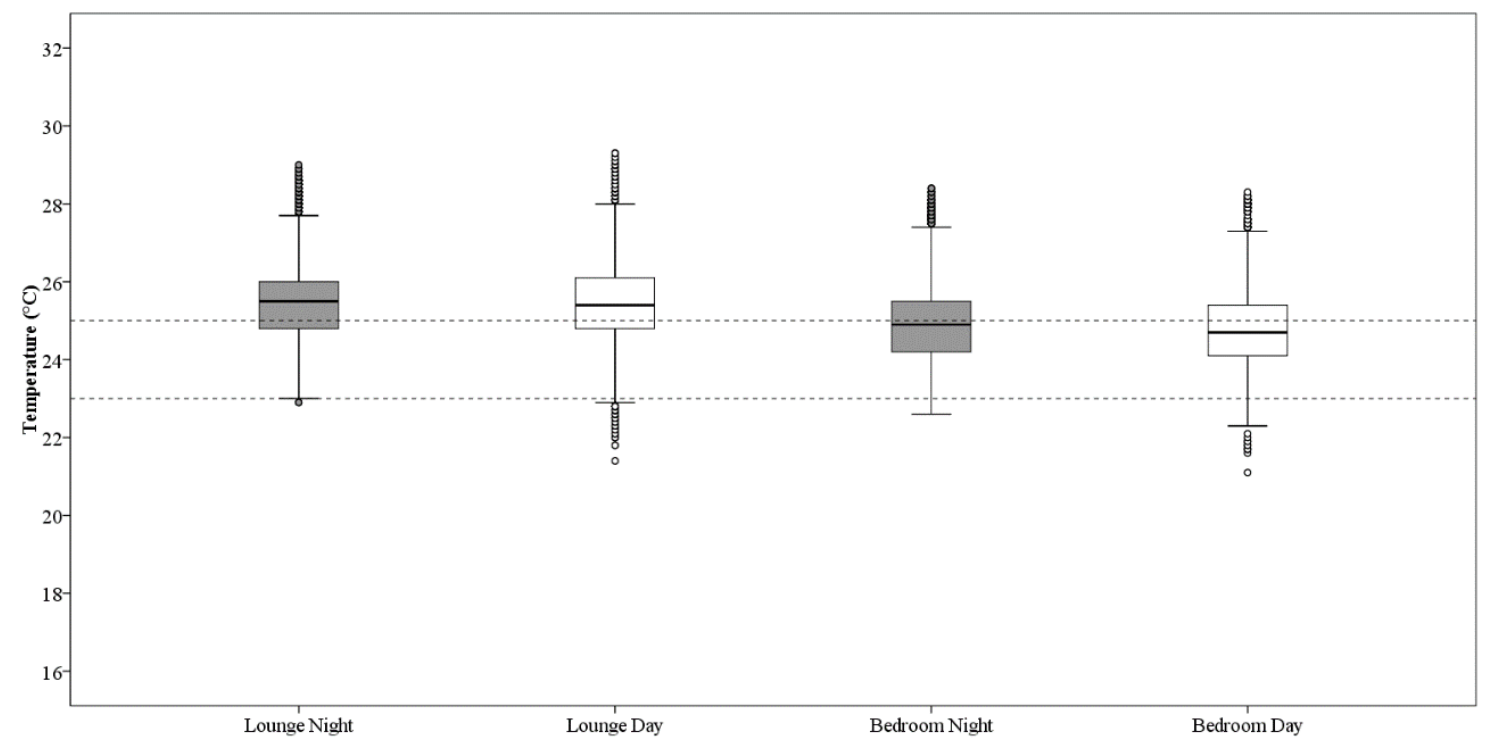

Figure 32014 temperature distribution in the lounge/kitchen area and bedroom.

A higher frequency of internal temperatures above the $25^{\circ} \mathrm{C}$ threshold were observed during 2013. This may in part be the result of external conditions during summer 2013, which experienced a heat wave between $3^{\text {rd }}$ to the $23^{\text {rd }}$ of July [53].

Figure 4 illustrates the higher frequency of warmer temperatures $\left(>20^{\circ} \mathrm{C}\right)$ during 2013 , which were predominantly recorded during the heat wave period. 

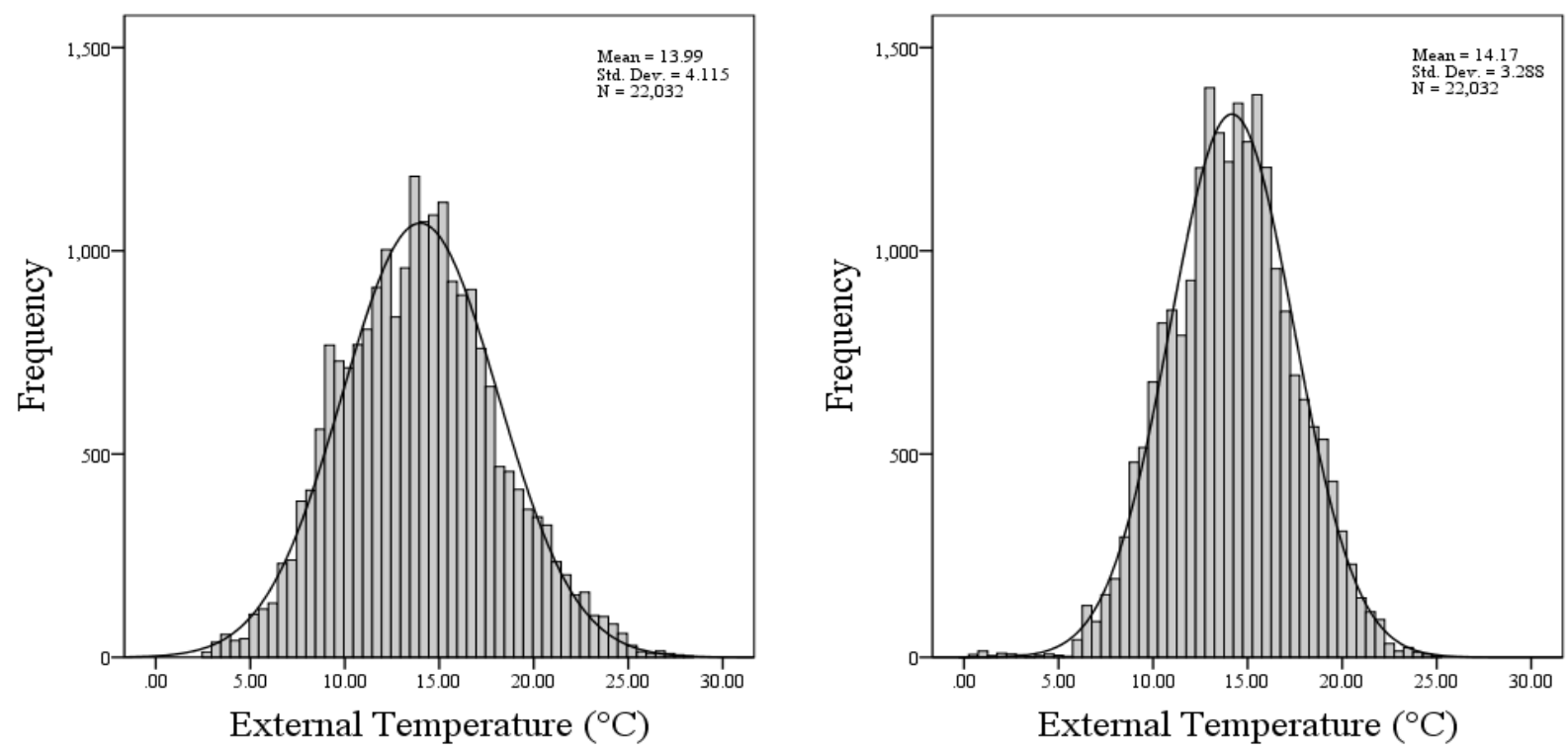

Figure 4 Comparison of external dry bulb temperature distribution for summer 2013 (Left) and summer 2014 (Right)

\subsection{Passive House Planning Package (PHPP)}

The Passive House Institute (PHI) criteria guidelines stipulate that overheating levels are acceptable if the "Percentage of hours in a given year with indoor temperatures above $25^{\circ} \mathrm{C}$ without active cooling $\leq 10 \%$ " [54]. The PHPP assessment completed for the case study dwelling identified an overheating frequency (where internal temperature was above the $25^{\circ} \mathrm{C}$ overheating limit) of $5 \%$ of total hours. Therefore, no recommendation for additional measures to protect against summer heat waves were made to the property. Monitored data during 2014, however, shows that the annual percentage of time above this PHPP overheating threshold was substantially higher than the recommended limits, as shown in Figure 5, particularly for the open plan lounge/kitchen area. Data from 2013 could not be considered for direct comparison due to the shorter monitoring period ( $<12$ months). Despite this, the data available from this period suggests a similarly high percentage of time above the PHPP overheating limit. 


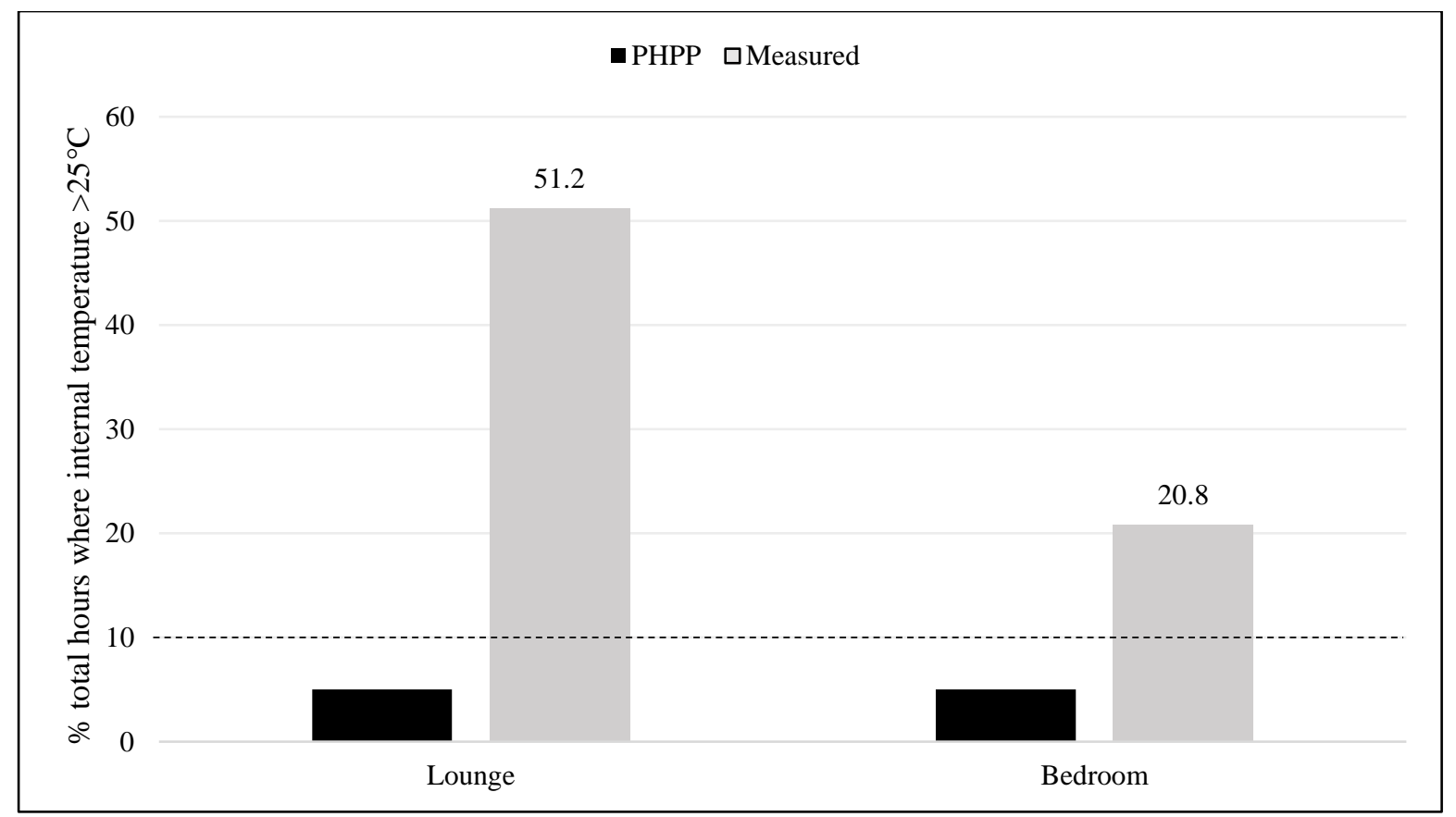

Figure 5 Comparison of PHPP prediction and measured time above the PHPP overheating threshold, with maximum limit given by dashed line.

The PHPP result may be primarily due to an underestimation of the internal heat loads. Monitored energy data, together with a DomEARM appliance audit, revealed energy consumption in situ to be far more weighted towards electrical appliances, such as televisions and computer equipment, than considered in PHPP. It is likely that the resulting additional internal heat gains will have contributed to the observed high internal temperatures.

\subsection{Adaptive thermal comfort}

Overheating was evaluated using the method described in CIBSE TM52 [46], derived from the adaptive comfort ISO 15251 [45] standard. The TM52 analysis method determines a comfort temperature $\left(T_{\text {comf }}\right)$ based on the exponentially weighted running mean external temperature $\left(T_{\mathrm{rm}}\right)$. The calculation for $T_{\text {comf }}$ is given such that:

$$
T_{\text {comf }}=0.33 T_{\mathrm{rm}}+18.8
$$


Where $T_{\mathrm{rm}}$ may be calculated following the process described in the Technical Memorandum [46]. In order to account for the inherently imprecise nature of thermal comfort judgement, a tolerance around $T_{\text {comf }}$ is specified for free-running buildings depending on the building type as described in Table 1.

Table 1 Suggested applicability of the categories and their associated temperature ranges for free-running buildings [45, 46]

\begin{tabular}{clc}
\hline Category & \multicolumn{1}{c}{ Explanation } & $\begin{array}{c}\text { Suggested acceptable } \\
\text { range (K) }\end{array}$ \\
\hline I & High level of expectation only used for spaces occupied by very & \pm 2 \\
II & sensitive and fragile persons & Normal expectation (for new buildings and renovations) \\
III & A moderate expectation (used for existing buildings) & \pm 3 \\
IV & Values outside the criteria for the above categories (only & $>4$ \\
\hline
\end{tabular}

The case study dwelling was determined as Category I to reflect the dwelling occupancy. As such, the maximum permissible temperature $T_{\max }$ at any given $T_{\mathrm{rm}}$ may be calculated following the below equation:

$$
T_{\max }=0.33 T_{\mathrm{rm}}+20.8
$$

TM52 uses operative temperature $\left(T_{\mathrm{op}}\right)$ to describe the internal temperature, and is a combination of dry bulb temperature $\left(T_{\mathrm{db}}\right)$ and mean radiant temperature $\left(T_{\mathrm{MRT}}\right)$. As only internal dry bulb temperature was monitored, it has been assumed that $T_{\mathrm{db}}=T_{\mathrm{MRT}}=T_{\mathrm{op}}$. The adoption of such an assumption is deemed to be appropriate, given the lightweight nature of the structure and absence of large sources of radiant heat. To test whether such an assumption is valid, a calibrated dynamic thermal simulation model was built, further details of which are described in Parker et al [55]. Modelled dry bulb and operative temperature relationship was observed to be $T_{\mathrm{op}}=1.0023 T_{\mathrm{db}}-0.0801$ with an $\mathrm{R}^{2}=0.9968$, and as such demonstrates a high correlation between measured and modelled temperatures thus supporting our assumption. 
Figure 6 and Figure 7 illustrate the acceptable temperature range for each $T_{\mathrm{rm}}$, presenting the adaptive comfort charts for the lounge/kitchen area and bedroom during each monitored year which have been generated following the protocol described in ISO 15251 [45]. These figures indicate a higher incidence of internal temperatures within the Category I comfort range at external temperatures exceeding $16^{\circ} \mathrm{C}$ during 2014 , suggesting cooling strategies were employed during warmer periods in 2014 with positive results.
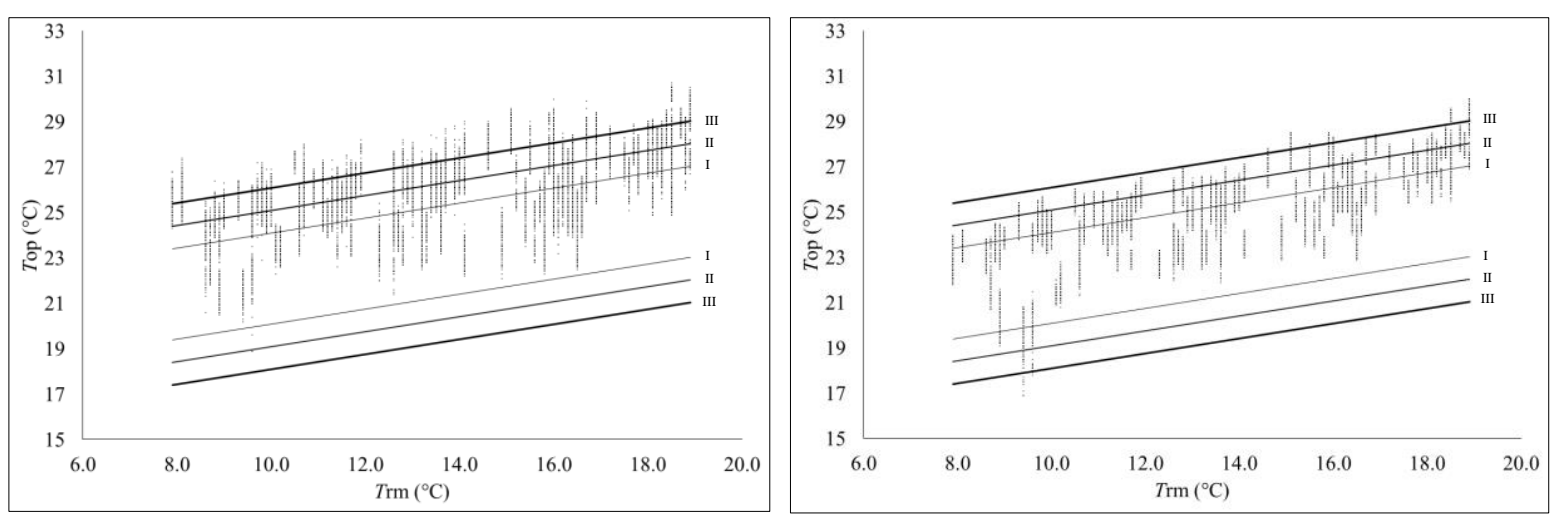

Figure 62013 ISO 15251 adaptive comfort charts for the dwelling lounge (left) and bedroom (right). Lines represent the upper and lower temperature thresholds for dwelling categories, with Category I denoted by the innermost lines.
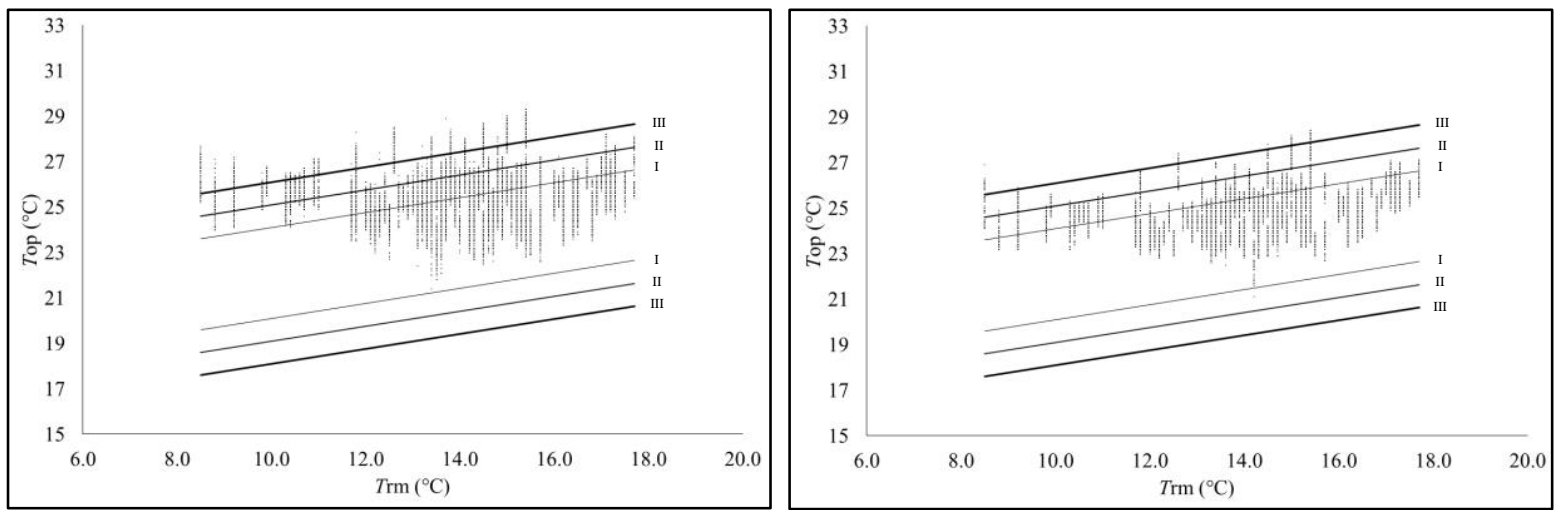
Figure 72014 ISO 15251 adaptive comfort charts for the dwelling lounge (left) and bedroom (right). Lines represent the upper and lower temperature thresholds for dwelling categories, with Category I denoted by the innermost lines.

The TM52 overheating assessment requires three criteria to be considered: Criteria 1 sets an hours of exceedance $\left(H_{\mathrm{e}}\right)$ limit of no more than $3 \%$ of occupied hours where the operative temperature $\left(T_{\mathrm{op}}\right)$ may exceed the maximum acceptable temperature $\left(T_{\max }\right)$ by $1 \mathrm{~K}$; Criteria 2 sets a limit on the severity of daily overheating using a weighted exceedance $\left(W_{\mathrm{e}}\right)$ where $W_{\mathrm{e}} \leq$ 6; Criteria 3 sets an absolute maximum daily temperature difference ( $\left.T_{\text {upp }}\right)$ of $\Delta T \leq 4 \mathrm{~K}$ where $\Delta T=T_{\text {op }}-T_{\text {max. }}$ The three criteria in TM52 have been abbreviated to C1 (Criteria 1), C2 (Criteria 2) and C3 (Criteria 3) in subsequent analysis.

Data for the TM52 assessment is considered from $1^{\text {st }}$ of May to the $30^{\text {th }}$ of September for each year, as required by $\mathrm{C} 1$. Overheating analysis methods are sensitive to occupancy schedules [46], specifically with regard to the determination of occupied hours. Whilst potentially representing an extreme scenario, 24 hour dwelling occupancy has been assumed, as 24 hour occupancy is consistent with the assumption in the PHPP overheating assessment and reasonably realistic for occupants with healthcare requirements. Within this whole dwelling occupancy, a sensitivity analysis is undertaken to compare the effect of zonal occupancy profiles on localised overheating, showing realistic experiential comfort under differing zonal occupancy.

The first profile (24 hour) assumes 24 hour occupancy of each zone i.e. an immobile occupant. The second profile (ISO) assesses the overheating risk in each zone during occupied hours according to the ISO occupancy schedule i.e. assuming that the lounge/kitchen area and bedroom were only occupied during the hours of 07:00-23:00 and 
23:00-07:00 respectively. The results of both analyses are discussed in the proceeding sections.

\subsubsection{Criteria 1}

The lounge/kitchen and the bedroom both experienced substantial hours of exceedance $\left(H_{\mathrm{e}}\right)$ where the operative temperature $\left(T_{\mathrm{op}}\right)$ exceeded the maximum acceptable temperature $\left(T_{\max }\right)$ by $1 \mathrm{~K}$. The maximum allowable $H_{\mathrm{e}}$ of $3 \%$ is illustrated in Figure 8 by the dashed line, together with the total percentage of $H_{\mathrm{e}}$ for each case. It is apparent that in all circumstances the $H_{\mathrm{e}}$ limit was breached, therefore $\mathrm{C} 1$ was failed.

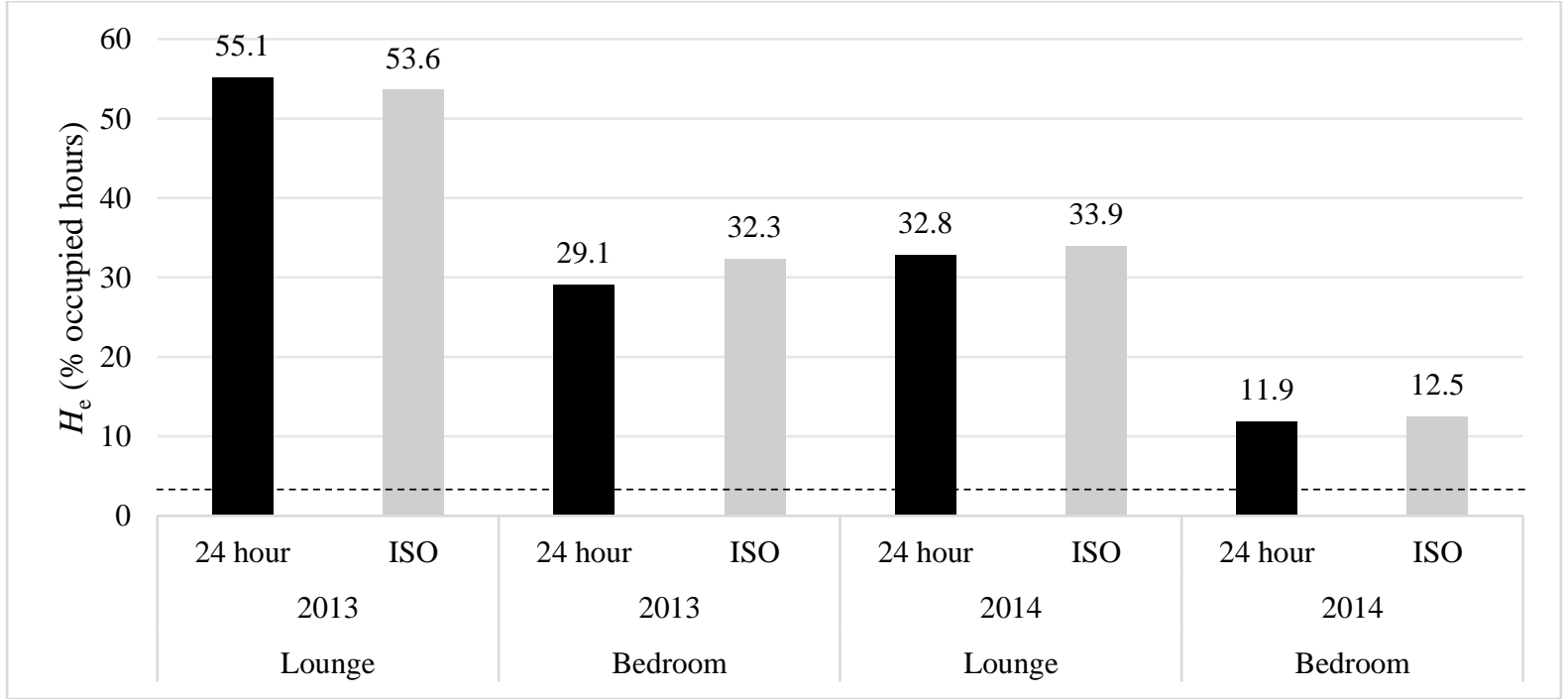

Figure 8 Percentage of occupied hours where operative temperature exceeds the maximum acceptable temperature by $1 \mathrm{~K}$

\subsubsection{Criteria 2}

C2 applies a weighted exceedance $\left(W_{\mathrm{e}}\right)$ to daily monitored temperatures to allow the severity of overheating to be considered, the calculation process for which is:

$$
W_{\mathrm{e}}=\sum\left(h_{\mathrm{ey}} \times W F\right)
$$




$$
W_{\mathrm{e}}=\left(h_{\mathrm{e} 0} \times 0\right)+\left(h_{\mathrm{e} 1} \times 1\right)+\left(h_{\mathrm{e} 2} \times 2\right)+\left(h_{\mathrm{e} 3} \times 3\right)
$$

Where $W F=0$ if $\Delta \mathrm{T} \leq 0$, otherwise $W F=\Delta \mathrm{T}$, and $h_{\mathrm{ey}}$ is the time $(h)$ when $W F=y$.

For each day the sum of $W_{\mathrm{e}}$ is calculated and should not exceed the limiting value of 6 to fulfil the $\mathrm{C} 2$ requirement. Figure 9 illustrates the percentage of total days during monitoring which exceeded the $W_{\mathrm{e}}$ maximum value. As can be seen, the $W_{\mathrm{e}}$ limit was exceeded in all circumstances and as such was failed.

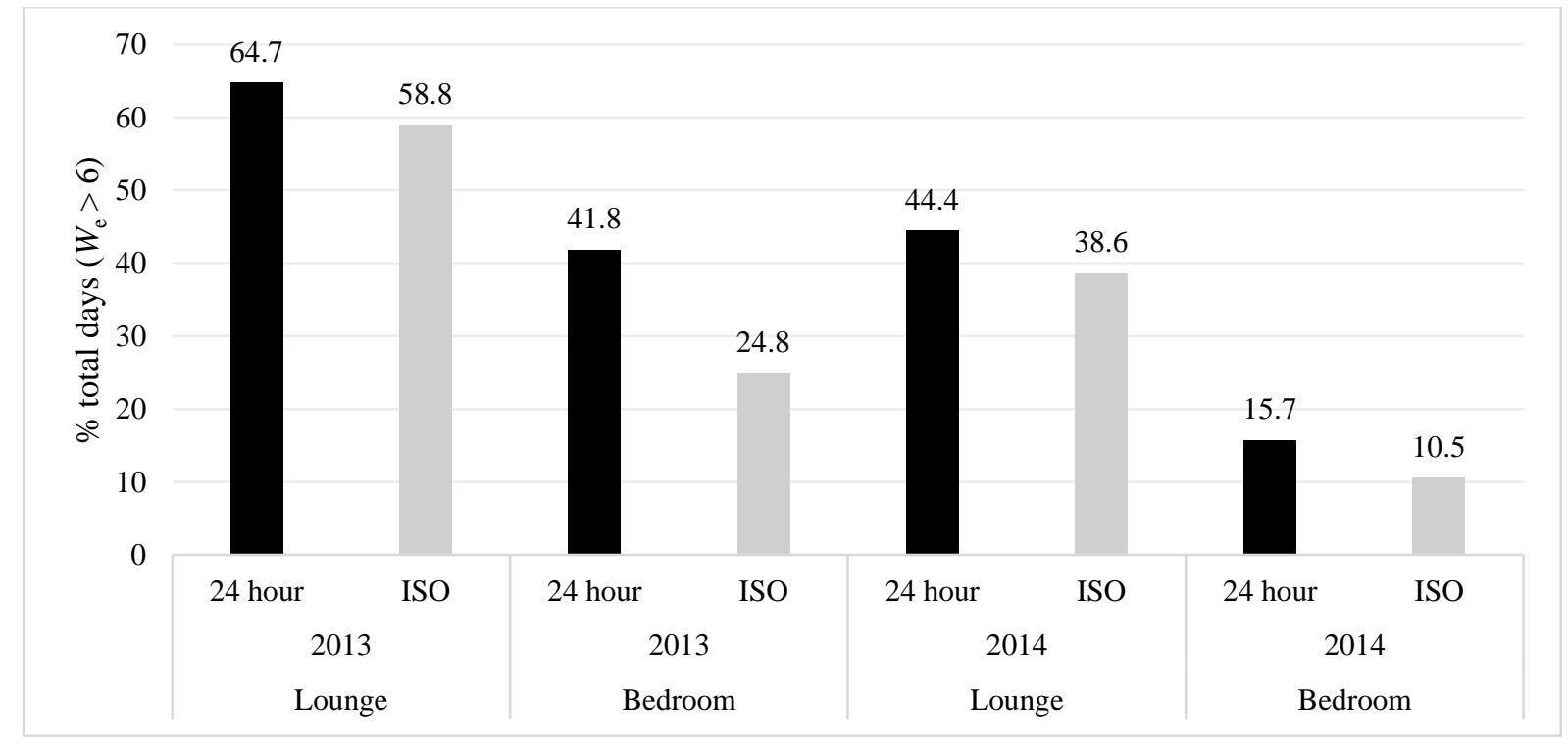

Figure 9 Percentage of total days within each monitored period where weighted exceedance $\left(\mathrm{W}_{\mathrm{e}}\right)$ exceeds limiting value.

\subsubsection{Criteria 3}

To fulfil C3 an upper temperature limit ( $\left.T_{\text {upp }}\right)$ is applied whereby the difference $(\Delta T)$ between operative temperature $\left(T_{\mathrm{op}}\right)$ and maximum acceptable temperature $\left(T_{\max }\right)$ should not exceed 4K. Figure 10 shows that whilst in several cases $T_{\text {upp }}$ was reached, at no point during the inuse monitoring was it exceeded. Consequently, the case study dwelling fulfilled C3. 


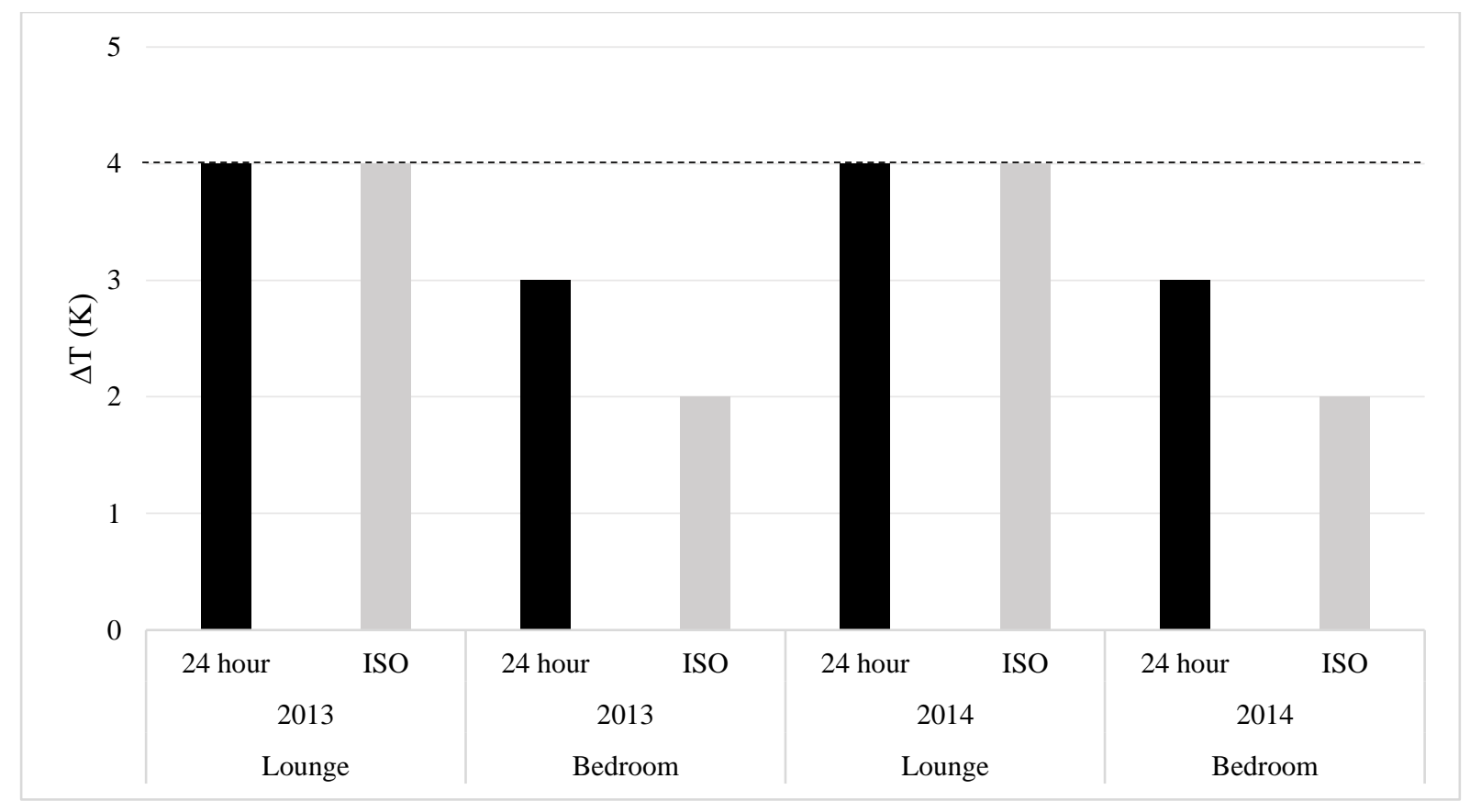

Figure 10 Maximum $\Delta \mathrm{T}$ during monitoring

As can be seen, the case study dwelling fails on both $\mathrm{C} 1$ and C2 of the TM52 assessment during both years, although there is an apparent reduction of overheating during 2014. As has been discussed in section 3.1, it is likely that the heat wave during 2013 influenced the higher overheating values displayed in the present analysis. However, the heat wave was of insufficient duration to fully account for the difference between the years. As shown by Johnston and Fletcher [47] there was little variation in electricity or heating use between both years, and thus aggregate internal heat gains may be considered to be similar in each year. Therefore, the additional decrease in overheating in 2014 is thought to be attributable to the occupant through increased cooling behaviour such as window opening for ventilation.

With regard to the zonal occupancies under consideration, notable reductions in $\mathrm{C} 2$ and $\mathrm{C} 3$ result are observed in the bedroom under ISO occupancy. This reduction is simply a product of daily maximum temperatures occurring during daytime hours; peak daily overheating is excluded from ISO bedroom analysis which assumes bedroom vacancy at these times, which 
may not always be the case in reality for vulnerable occupants with mobility issues. It is apparent that the considered occupancy profiles affect the individual values but not the overall result i.e. the success or failure to meet criteria requirements. Part of the reason for this is thought to be attributable to the lack of any diurnal variation in the dry bulb temperature throughout the dwelling.

\subsection{Temporal static overheating assessment}

The adaptive comfort assessment incorporates the theory that the combined influence of psychological, physiological and behavioural adaptation permits a comfort temperature relative to the external temperature [45]. This limits the application of the methodology for assessing overheating during colder periods, such as the heating season, as indoor temperatures within what are commonly regarded as 'acceptable' limits would appear to indicate that overheating is occurring due to the much larger internal/external temperature difference. In the context of this research, the observed high internal temperatures were not limited to the summer period, and required additional investigation.

Static overheating limits, such as that described in CIBSE Environmental Design Guide A [56], whilst not able to describe the severity of overheating, are not influenced by a dynamic threshold temperature relative to the external environment and may, therefore, be used to describe the overall overheating experienced during the monitored period. The guide recommends that summer operative temperatures $\left(T_{\mathrm{op}}\right)$ in the lounge/kitchen area and bedroom should not exceed $28^{\circ} \mathrm{C}$ and $26^{\circ} \mathrm{C}$ respectively for more than $1 \%$ of total occupied hours. The results of this assessment for the case study dwelling are presented in Figure 11. As can be seen, the percentage of total occupied hours exceeding these threshold 
temperatures during the two monitored summer periods in each zone under both occupancy profiles is greater than the $1 \%$ limit in all instances.

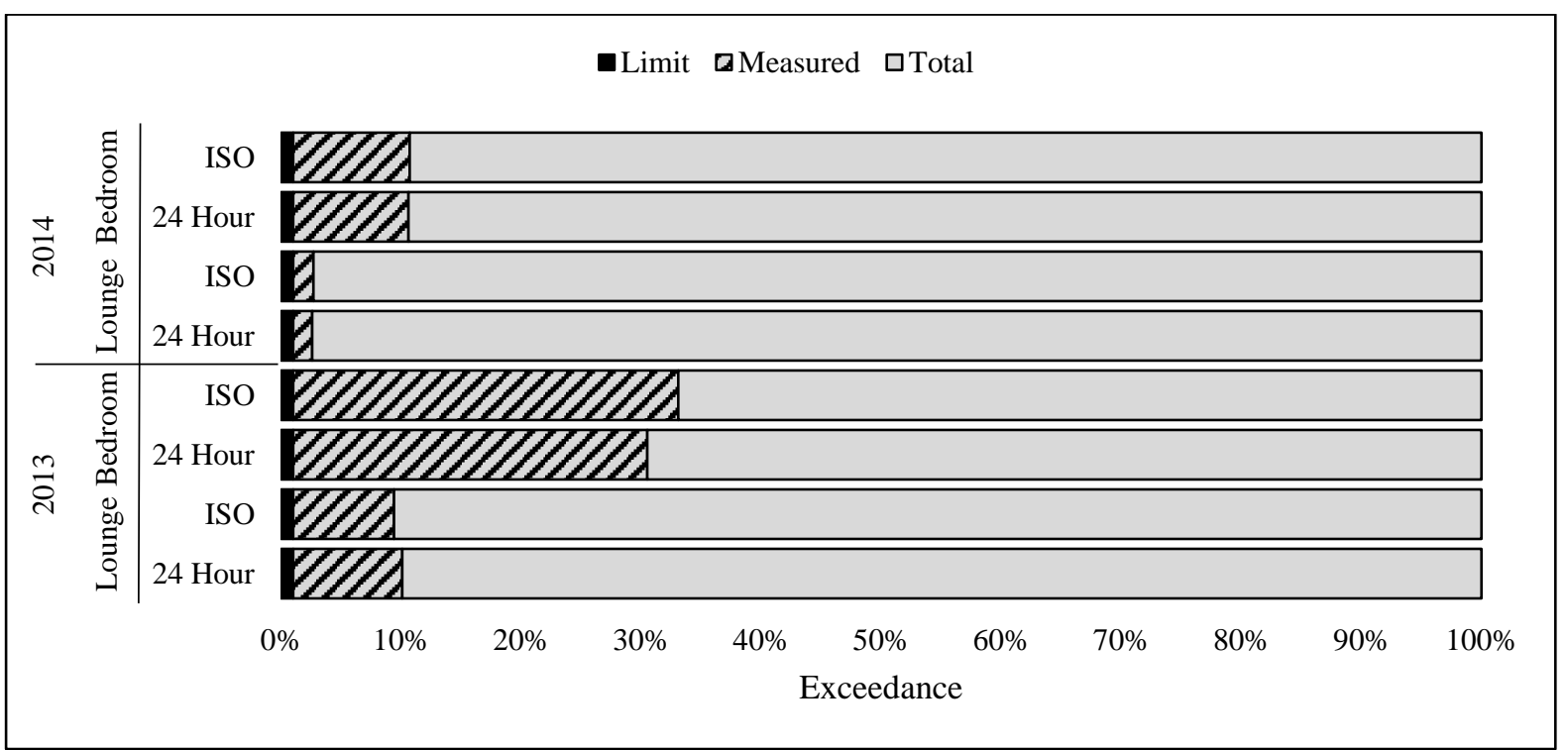

Figure 11 Percentage of occupied hours above CIBSE Guide A (2006) temperature thresholds

By disaggregating the above method and considering threshold exceedance per day, as opposed to total exceedance during summer, it is possible to observe the seasonal temporal occurrence of overheating, namely the specific days where overheating thresholds were exceeded. Critically, such an approach may be used to assess winter overheating by applying plausible static threshold temperatures. For this analysis, threshold operative temperatures were taken from the CIBSE Guide A [56] guidance, with the lounge/kitchen area and bedroom set at $28^{\circ} \mathrm{C}$ and $26^{\circ} \mathrm{C}$ respectively. An exceedance value was set to a maximum of $3 \%$ of occupied hours, which corresponds to a practical limit of 50 minutes per day above the threshold temperature under 24-hour occupancy due to the 10 minute resolution of the data. In order to acknowledge the influence of occupancy schedules in such an analysis, the ISO schedule was also applied to the lounge/kitchen area (07:00-23:00) and bedroom (23:0007:00), with practical daily exceedance limits of 30 minutes and 20 minutes respectively, in 
order to align with the relative weighting applied by the ISO profiles. A 3\% threshold was chosen as it provides a reasonable estimation of acceptable exposure duration during a single day, and is consistent with the Zero Carbon Hub [57] guidance. However, as noted above the authors acknowledge that static thresholds do not indicate severity, therefore days experiencing excessive overheating for durations shorter than the aforementioned exceedance limits will not be revealed by the following analysis.

For subsequent analysis, nomenclature of location and schedule is given such that: $\mathrm{L}_{24}$ is the Lounge/Kitchen under 24 hour occupancy; $\mathrm{B}_{24}$ is the Bedroom under 24 hour occupancy; $\mathrm{L}_{\text {ISO }}$ is the Lounge/Kitchen under ISO schedule occupancy and $\mathrm{B}_{\text {ISO }}$ is the Bedroom under ISO schedule occupancy.

The black segments in Figure 12Figure 13 indicate individual days where internal temperatures exceeded the daily maximum temperature duration limits described above and are therefore regarded as experiencing overheating. For reference, the non-heating season $\left(1^{\text {st }}\right.$ May- $30^{\text {st }}$ September) which is typically the focus of overheating analysis [46] is highlighted by the hashed box. It is clear that days with temperatures exceeding the thresholds occur during the colder seasons also, although to a lesser extent. Although it is established in the literature that elderly occupants prefer a warmer internal environment and thus the warmer internal temperature may be the result of the occupant's thermostat settings, it is unlikely that the maximum thresholds used during this analysis would be exceeded intentionally. 


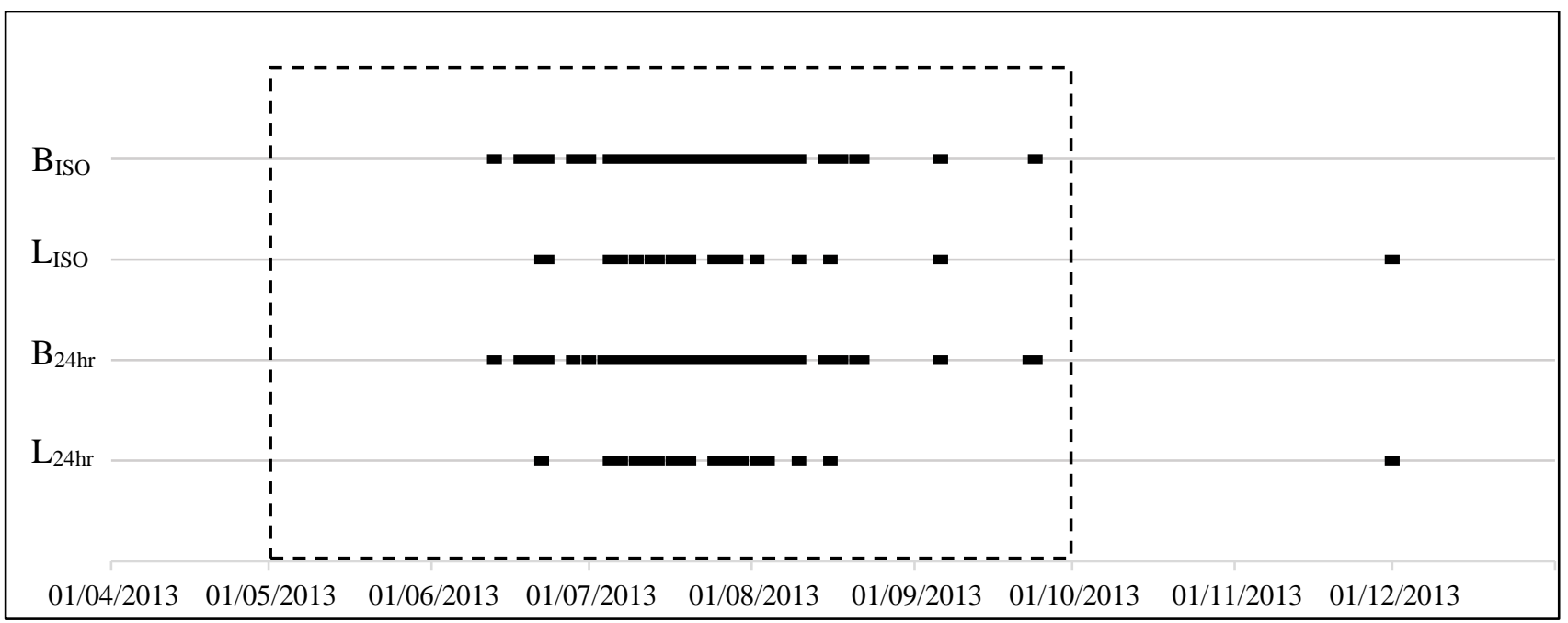

Figure 122013 Daily exceedance beyond static threshold limits

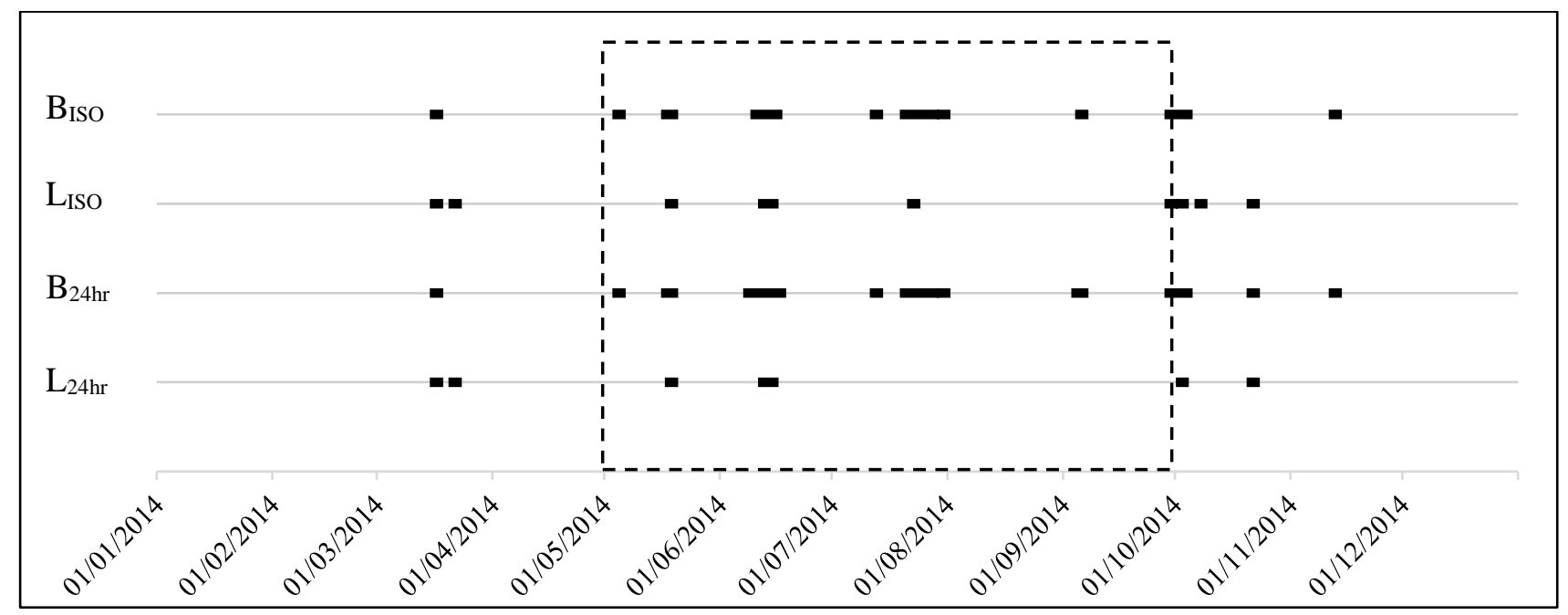

Figure 132014 Daily exceedance beyond static threshold limits

As mentioned, this analysis only highlights when periods of overheating occur and does not indicate severity, which has obvious implications on acceptable exposure duration. In order to account for this, analysis similar to C2 in TM52 [46] was undertaken, applying weighted significance to temperatures based on the extent to which the threshold was exceeded i.e. the temperature difference between the internal operative temperature and the maximum 
threshold temperature. The process for this followed the same weighting as in TM52 as defined above, however the maximum temperature was fixed for the lounge/kitchen area and bedroom as $28^{\circ} \mathrm{C}$ and $26^{\circ} \mathrm{C}$ respectively rather than calculated based on external temperature. Additionally, the weighted exceedance ( $W_{\mathrm{e}}$ ) daily limit was reduced to $W_{\mathrm{e}} \leq 1$ in response to the high maximum temperature used, in order to reflect the severity of overheating and reduce acceptable exposure accordingly.

The distribution and magnitude of $W_{\mathrm{e}}$ for individual days where $W_{\mathrm{e}}>1$ during the monitored period are displayed in Figure 14 Figure 15. A high daily $W_{\mathrm{e}}$ is indicative of sustained time and/or considerable temperature above the maximum temperature threshold. As expected, the greatest severity of overheating occurs during the summer months which have warmer mean daily external temperatures; an extreme example being the heat wave in July 2013. Notably, there are also instances of excessive $W_{\mathrm{e}}$ during colder months, albeit to a lesser severity, suggesting overheating periods during these times are not exclusively limited to mild or short-term events. Whilst it is apparent that $W_{\mathrm{e}}$ is predominantly related to external temperature, the occurrence of overheating during colder months suggests that occupancy factors also play a role in overheating events.

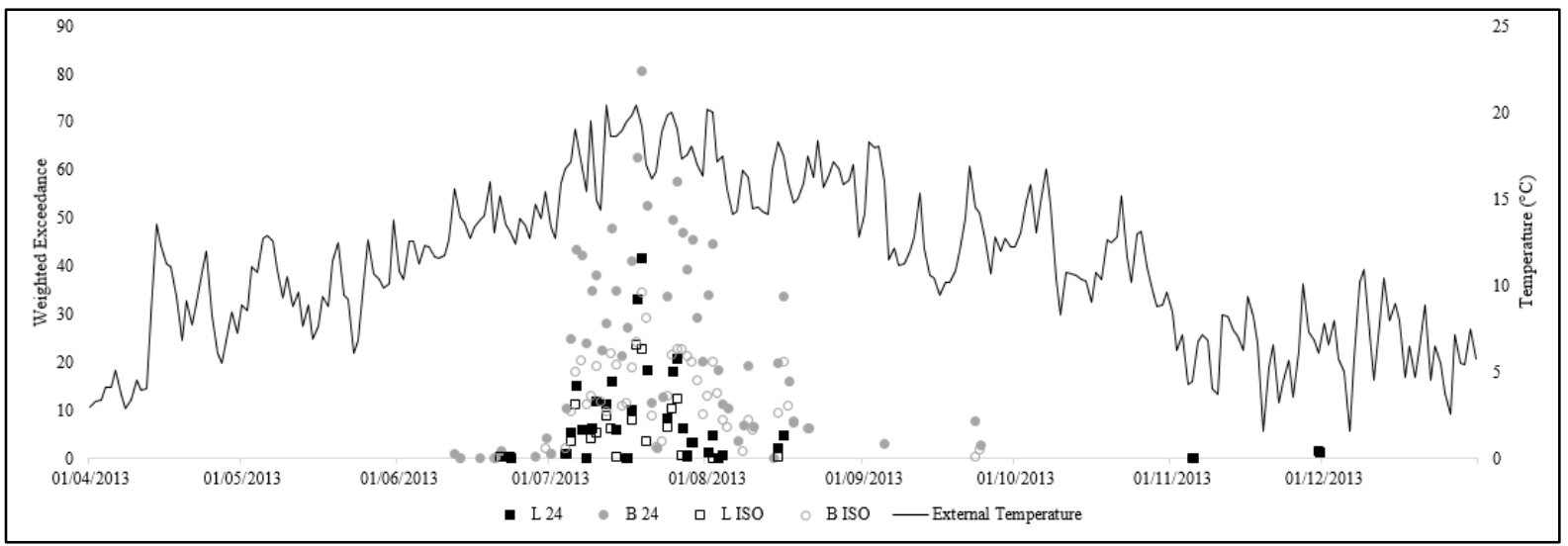

Figure 142013 distribution of daily weighted exceedance 


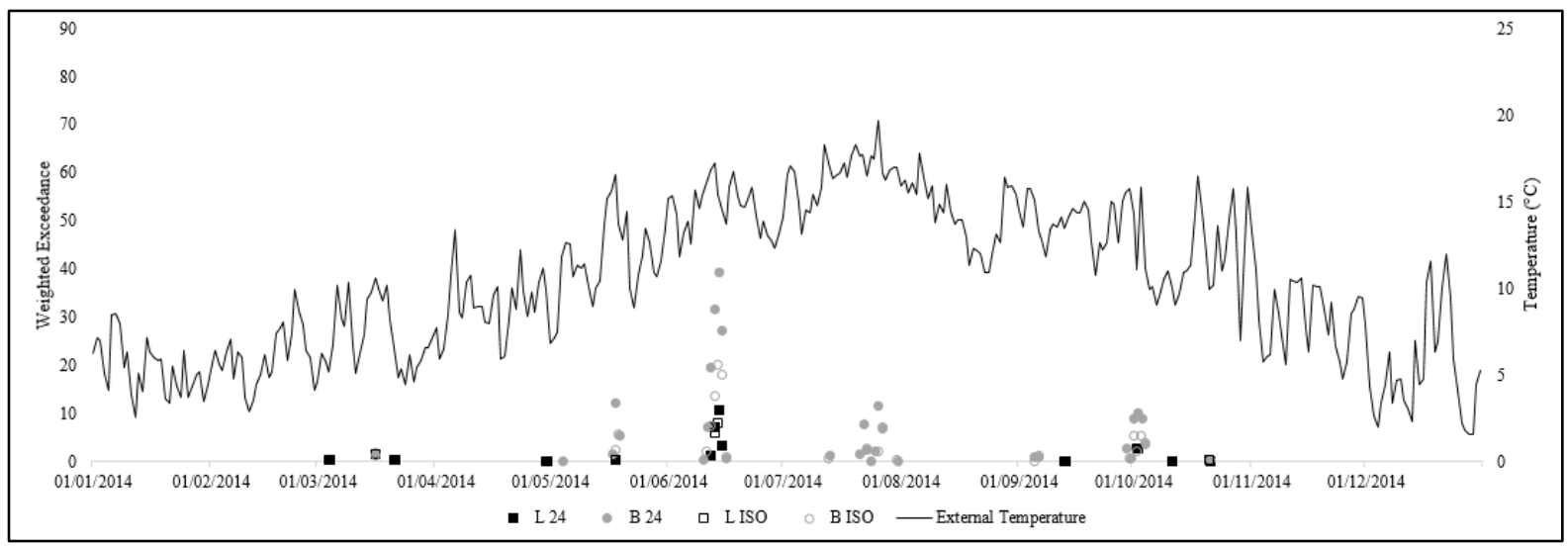

Figure 152014 distribution of daily weighted exceedance

Although an adaptive approach is more commonly used in the thermal comfort assessment of free running dwellings, recent literature suggests that static thresholds still remain relevant. This is particularly the case during periods where adaptive behaviours are restricted such as during sleep [31], an assertion supported by the Zero Carbon Hub [57]. The occurrence of daily temporal overheating, and specifically night-time overheating, is an issue of growing concern, with existing UK evidence suggesting that quality of sleep is affected at temperatures above $24^{\circ} \mathrm{C}$ even in cooler months [58]. Guidance is also available that suggests that in the absence of a means to create air movement, temperatures should be kept below $26^{\circ} \mathrm{C}$ [51]. The importance of this is enhanced when considering the specific context of the case study dwelling: a care setting with elderly residents [59]. The above analysis identifies that under maximum static threshold temperature analysis, the case study bedroom experiences substantial overheating in terms of both duration and severity, even when only considering non-summer night-time occupancy hours.

\section{Discussion}

Although it is only possible to make a number of qualitative comments due to the sole and non-random nature of the case study dwelling that was monitored, the results indicate that temperatures within the case study dwelling were predominantly above recommend limits 
[51]. Measured temperatures were observed to substantially exceed the overheating prediction generated by the PHPP calculation. It is thought that this was due to an underestimation of internal heat gains from electrical appliances. As such, this offers evidence of the importance of accurately accounting for internal heat loads during predictive assessments of Passivhaus buildings.

Adaptive comfort assessment following the method described in TM52 [46] was conducted for the summer period of both monitored years. Analysis considered both 24 hour and daytime/night-time occupancy in the separate zones of the dwelling in order to assess the influence of schedules on the assessment result. The results suggested that the case study dwelling experienced overheating under both occupancy schedules, with Criteria 1 and Criteria 2 of the TM52 assessment failing in all cases. It was apparent that the occupancy patterns affected individual criteria results, but not the overall result i.e. the success or failure to meet criteria requirements. This is an important finding, as part of the reason for this is felt to be attributable to the lack of any diurnal variation in the dry bulb temperature throughout the dwelling, a feature typical in Passivhaus dwellings. The observed reduction of overheating in the second year of monitoring, particularly during warmer external conditions as illustrated in section 3.3, suggests a change in cooling behaviour. This may be due to familiarity with the dwelling, or be indicative of pre-emptive cooling based on previous experience.

A composite analysis drawing from existing static and adaptive overheating assessment methods was proposed in order to conduct overheating assessment during periods not currently considered as at risk of overheating. This encompassed an approach to assess daily overheating, which considered both duration and severity. 
One of the most important findings to be obtained from this analysis was the emergence of empirical data that not only indicates that Passivhaus dwellings can suffer from significant overheating during the summer months, but that they can also experience overheating during periods which are not commonly considered to be at risk, i.e. colder months. This seasonal temporal overheating is believed to occur due to a combination of factors, such as high levels of thermal insulation and airtightness, a design optimised for passive gains, high internal heat gains, and in this particular case, low thermal mass, resulting in heat accumulation and retention beyond that of a typical dwelling. This has implications for the overheating assessment of such dwellings, and the subsequent strategies employed to reduce overheating.

The occurrence of winter overheating also has important considerations for the control and conditioning systems installed within Passivhaus dwellings. For instance, control systems for space heating systems should be installed with maximum temperature threshold settings to prevent the occurrence of winter overheating. Additionally, the presence of an MVHR system may lead to the undesirable retention of heat in the dwelling, and care must be taken to ensure that bypass functions, which are typically only considered to be operated during the summer periods, are controlled according to internal temperature. Assuming heat recovery is employed continuously during colder months, the sporadic nature of winter overheating described in this paper suggests a risk of competing conditioning strategies. For example, an occupant opening windows to provide cooling during periods when the MVHR is in heat recovery mode, leading to system inefficiencies and increased energy use.

Winter overheating also presents a problem with regards to the adaptive response of residents following the principles described in ISO 15251 [45]. According to the adaptive response method identified within ISO 15251, occupants are much more likely to be sensitive to higher temperatures during colder periods, which could lead to an enhanced level of discomfort.

This is a scenario which requires further investigation. 
The static threshold analysis presented in this paper also reveals the occurrence of daily temporal overheating, specifically night-time overheating in the dwelling bedroom, providing further evidence to support a detailed review on the appropriateness of existing comfort methods in assessing thermal comfort during sleep. Further research is required to establish acceptable exceedance limits at a daily resolution. Additionally, Passivhaus design should consider the cumulative effect of gains and their impact in the absence of overnight purging, with specific attention given to the barriers associated with effective cooling strategies, a situation exacerbated during night-time periods where acceptable adaptation opportunities are reduced.

The assumption has been made that temperatures above the CIBSE maximum limits are undesirable, however in the absence of thermostat set point data or occupant thermal perception at the point of threshold exceedance the authors are unable to empirically validate this. In the event that the occupants find such temperatures comfortable or are simply not aware of the temperature severity, there arises a divergence between occupant behaviour to achieve comfort and their healthcare requirements. This suggests a need for automated cooling systems in assisted living dwellings.

It is relevant to note that all overheating methods presented in this paper are based on current standards, which do not have a special classification for the elderly beyond specifying a strict Category I temperature band in the adaptive comfort analysis. It is established in the literature that elderly people have a different thermal preference to the general population, therefore there exists a need for further research to establish specific thermal comfort criteria for the elderly. This should be influenced by the healthcare requirements and age-specific limitations of the elderly population, in addition to individual preference. 
Crucially, it is important to acknowledge the effect of occupancy on overheating; a 24 hour dwelling occupancy may be regarded as a worst case scenario, albeit realistic in the context of this analysis. Additionally, it was not possible to empirically validate the levels of natural ventilation cooling during this study. However the findings of Parker et al [55] suggest that an extensive natural ventilation regime would theoretically enable the dwelling to satisfy comfort requirements. It should be noted, however, that the nature of the dwelling and occupants may have prevented necessary ventilation. For example, security concerns related to the opening of ground floor windows.

\section{Conclusion}

This paper has presented the results obtained from an in-use monitoring study of an assisted living Passivhaus dwelling in the UK. Adaptive and static overheating analyses have been undertaken to show the temporal aspects of overheating, with additional consideration of the influence attributed to the occupancy profile.

A composite method was applied to overcome the limitation of the adaptive method for overheating assessment during the heating season, and from this the dwelling was observed to experience overheating beyond the periods typically considered by existing overheating assessments.

The implication of this finding is that even with a large temperature difference between the internal and external environment, overheating can occur if the dwelling is not managed correctly. This has added significance when considering the additional health risk posed by overheating to the residents of assisted living properties.

Passivhaus dwellings offer an excellent opportunity for the reduction of heating energy requirement and are a legitimate route to achieving energy and carbon reduction targets. It is 
imperative, however, that energy and carbon savings do not come at the expense of occupant thermal comfort.

\section{Acknowledgements}

The authors gratefully acknowledge the funding provided by the Technology Strategy Board (now Innovate UK) as part of its Building Performance Evaluation Programme [project number 450070]. This funding was used to undertake the in-use monitoring on the case study dwelling identified within this paper.

\section{References}

[1] UNFCCC, The Paris Agreement United Nations Framework Convention on Climate Change, 2016. [2] UNEP, Building Design and Construction: Forging Resource Efficiency and Sustainable Development, in: M. Comstock, C. Garrigan, S. Pouffary (Eds.) United Nations Environment Programme, 2012.

[3] J. Palmer, I. Cooper, United Kingdom housing energy fact file, in: D.o.e.a.C. Change (Ed.) TSO, London, 2013.

[4] DCLG, Approved Document L1B: conservation of fuel and power in existing dwellings: 2010 edition, Department for Communities and Local Government, London, 2010.

[5] DCLG, Approved Document L1A: conservation of fuel and power in new dwellings: 2013 edition Department for Communities and Local Government, London, 2013.

[6] W. Feist, J. Schnieders, V. Dorer, A. Haas, Re-inventing air heating: Convenient and comfortable within the frame of the Passive House concept, Energy \& Buildings 37 (2005) 1186-1203.

[7] J. Williamson, Domestic Passivhaus - First to be certified in the UK, Green Building Magazine, 2009, p. 3.

[8] Passivhaus Trust, Passivhaus Trust Project Gallery, 2017.

http://www. passivhaustrust.org.uk/projects/. (Accessed 2nd February 2017).

[9] Zero Carbon Hub, Overheating in Homes: The Big Picture, Zero Carbon Hub, London, 2015. [10] BRE, SAP 2012. The Government's Standard Assessment Procedure for Energy Rating of Dwellings 2012, Building Research Establishment, UK, 2017.

[11] BRE, BREEAM: BRE Environmental Assessment Method, Building Research Establishment UK, 2017.

[12] A. Beizaee, K.J. Lomas, S.K. Firth, National survey of summertime temperatures and overheating risk in English homes, Building and Environment 65 (2013) 1-17.

[13] D. Coley, T. Kershaw, Changes in internal temperatures within the built environment as a response to a changing climate, Building and Environment 45(1) (2010) 89-93.

[14] A. Dengel, M. Swainston, Overheating in new homes: A review of the evidence, NHBC Foundation, Milton Keynes, 2012.

[15] R. Gupta, M. Gregg, K. Williams, Cooling the UK housing stock post-2050s, Building Services Engineering Research \& Technology 36(2) (2015) 196-220. 
[16] R. Gupta, M. Kapsali, Empirical assessment of indoor air quality and overheating in low-carbon social housing dwellings in England, UK, Advances in Building Energy Research (2015).

[17] K.J. Lomas, T. Kane, Summertime temperatures and thermal comfort in UK homes, Building Research \& Information 41(3) (2013) 259-280.

[18] R.V. Jones, S. Goodhew, P. de Wilde, Measured Indoor Temperatures, Thermal Comfort and Overheating Risk: Post-occupancy Evaluation of Low Energy Houses in the UK, Energy Procedia 88 (2016) 714-720.

[19] S. Pretlove, S. Kade, Post occupancy evaluation of social housing designed and built to Code for Sustainable Homes levels 3, 4 and 5, Energy and Buildings 110 (2016) 120-134.

[20] S.M. Tabatabaei Sameni, M. Gaterell, A. Montazami, A. Ahmed, Overheating investigation in UK social housing flats built to the Passivhaus standard, Building and Environment 92 (2015) 222-235.

[21] I. Ridley, A. Clarke, J. Bere, H. Altamirano, S. Lewis, M. Durdev, A. Farr, The monitored performance of the first new London dwelling certified to the Passive House standard, Energy and Buildings 63 (2013) 67-78.

[22] Cambridge Architectural Research Ltd, 450019 Future Works Passivhauses - Final Report, Domestic Buildings, Phase 1: Post construction and early occupation. A report to Innovate UK as part of the Building Performance Evaluation Programme, Digital Catapult, London, 2012.

[23] O. Guerra-Santin, C. Tweed, H. Jenkins, S. Jiang, Monitoring the performance of low energy dwellings: Two UK case studies, Energy and Buildings 64 (2013) 32-40.

[24] M. Derbez, B. Berthineau, V. Cochet, C. Pignon, J. Ribéron, G. Wyart, C. Mandin, S. Kirchner, A 3year follow-up of indoor air quality and comfort in two energy-efficient houses, Building and Environment 82 (2014) 288-299.

[25] T.S. Larsen, R.L. Jensen, O. Daniels, The Comfort Houses - Measurements and analysis of the indoor environment and energy consumption in 8 passive houses 2008-2011, DCE Technical Report, Aalborg, 2012.

[26] R.S. McLeod, C.J. Hopfe, A. Kwan, An investigation into future performance and overheating risks in Passivhaus dwellings, Building and Environment 70 (2013) 189-209.

[27] V.D. Meulenaer, H. Hens, Performance assessment of "passive houses" based on extensive measurement., Department of Civil Engineering, Leuven, 2005.

[28] E. Mlecnik, T. Schütze, S.J.T. Jansen, G. de Vries, H.J. Visscher, A. van Hal, End-user experiences in nearly zero-energy houses, Energy \& Buildings 49 (2012) 471-478.

[29] G. Rojas, W. Wagner, J. Suschek-Berger, R. Pfluger, W. Feist, Applying the passive house concept to a social housing project in Austria - evaluation of the indoor environment based on long-term measurements and user surveys, Advances in Building Energy Research 10(1) (2016) 125.

[30] W. Feist, S. Peper, M. Gorg, CEPHEUS Final Technical Report, Passiv Haus Institut, Vorarlberg, 2001.

[31] R. Gupta, L. Barnfield, M. Gregg, Overheating in care settings: magnitude, causes, preparedness and remedies, Building Research \& Information 45(1-2) (2017) 83-101.

[32] M. Vellei, A.P. Ramallo-González, D. Coley, J. Lee, E. Gabe-Thomas, T. Lovett, S. Natarajan, Overheating in vulnerable and non-vulnerable households, Building Research \& Information 45(1-2) (2017) 102-118.

[33] N.E. Klepeis, W.C. Nelson, W.R. Ott, J.P. Robinson, A.M. Tsang, P. Switzer, J.V. Behar, S.C. Hern, W.H. Engelmann, The National Human Activity Pattern Survey (NHAPS): a resource for assessing exposure to environmental pollutants, Journal of exposure analysis and environmental epidemiology 11(3) (2001) 231-52.

[34] M. Almeida-Silva, H.T. Wolterbeek, S.M. Almeida, Elderly exposure to indoor air pollutants, Atmospheric Environment 85 (2014) 54-63.

[35] L. Schellen, W.D. Van Marken Lichtenbelt, M.G.L.C. Loomans, J. Toftum, M.H. De Wit, Differences between young adults and elderly in thermal comfort, productivity, and thermal physiology in response to a moderate temperature drift and a steady-state condition, Indoor Air 20(4) (2010) 273-283. 
[36] D.V. Bates, Why do older patients die in a heatwave?, QJM: An International Journal of Medicine 98(11) (2005) 840-841.

[37] Y. Jiao, H. Yu, T. Wang, Y. An, Y. Yu, Thermal comfort and adaptation of the elderly in freerunning environments in Shanghai, China, Building and Environment 118 (2017) 259-272.

[38] R.L. Hwang, C.P. Chen, Field study on behaviors and adaptation of elderly people and their thermal comfort requirements in residential environments, Indoor Air 20(3) (2010) 235-245.

[39] J. van Hoof, H.S.M. Kort, J.L.M. Hensen, M.S.H. Duijnstee, P.G.S. Rutten, Thermal comfort and the integrated design of homes for older people with dementia, Building and Environment 45 (2010) 358-370.

[40] V. Abrahamson, J. Wolf, I. Lorenzoni, B. Fenn, S. Kovats, P. Wilkinson, W.N. Adger, R. Raine, Perceptions of heatwave risks to health: interview-based study of older people in London and Norwich, UK, Journal of Public Health 31(1) (2009) 119-126.

[41] J. Yang, I. Nam, J.-R. Sohn, The influence of seasonal characteristics in elderly thermal comfort in Korea, Energy and Buildings 128 (2016) 583-591.

[42] N. Zhang, B. Cao, Z. Wang, Y. Zhu, B. Lin, A comparison of winter indoor thermal environment and thermal comfort between regions in Europe, North America, and Asia, Building and Environment 117 (2017) 208-217.

[43] J. Schnieders, CEPHEUS - measurement results from more than 100 dweling units in passive houses. European Council for an Energy Efficient Economy (ECEEE) Summer Study, Stockholm, 2003. [44] J. Schnieders, A. Hermelink, CEPHEUS results: measurements and occupants' satisfaction provide evidence for Passive Houses being an option for sustainable building, Energy Policy 34 (2006) 151-171.

[45] BSI, BS EN 15251:2007 Indoor environmental input parameters for design and assessment of energy performance of buildings addressing indoor air quality, thermal environment, lighting and acoustics, British Standards Institution, LONDON, 2008.

[46] CIBSE, CIBSE TM52: 2013 The limits of thermal comfort: avoiding overheating in European buildings, The Chartered Institution of Building Services Engineers, London, 2013.

[47] D.K. Johnston, M. Fletcher, TSB BPE Project 450070 - Gentoo Racecourse, Sunderland. TSB BPE Phase 2 Final Report: In-use Performance and Post Occupancy Evaluation Technology Strategy Board / Leeds Beckett University, 2015.

[48] ATTMA, ATTMA Technical Standard L1, Measuring the air permeability of building envelopes (Dwellings): October 2010 Issue, Air Tightness Testing and Measurement Association, Northampton, UK, 2010.

[49] J. Wingfield, D. Johnston, D. Miles-Shenton, M. Bell, Whole House Heat Loss Test Method Coheating, Leeds Metropolitan University, Leeds, 2010.

[50] BSI, ISO 9869:1994 In-situ measurement of thermal resistance and thermal transmittance, Switzerland, 1994.

[51] CIBSE, Environmental Design Guide A, CIBSE Publications, London, 2016.

[52] BSI, BS EN 13790:2008 Energy performance of buildings - Calculation of energy use for space heating and cooling, British Standards Institution, London, UK, 2008.

[53] MET Office, July 2013 Heat Wave, 2013.

http://www.metoffice.gov.uk/climate/uk/interesting/2013-heatwave. (Accessed 2nd May 2017 2017).

[54] Passive House Institute, Criteria for the Passive House, EnerPHit and PHI Low Energy Building Standard, Passive House Institute, Darmstadt, Germany, 2015, p. 13.

[55] J.M. Parker, M. Fletcher, D.K. Johnston, Predicting future overheating in a Passivhaus dwelling using a calibrated dynamic thermal simulation models Sustainable Ecological Engineering Design for Society (SEEDS) Annual Conference 2016, Leeds, UK, 2016.

[56] CIBSE, Environmental Design Guide A, CIBSE Publications, London, 2006.

[57] Zero Carbon Hub, Next steps in defining overheating: A discussion paper, ZCH, London, 2016. 
[58] M.A. Humphreys, The influence of season and ambient temperature on human clothing behaviour, in: P.O. Fanger, O. Valbjorn (Eds.), Indoor Climate, Danish Building Research, Copenhagen, 1979.

[59] K. Tsuzuki, I. Mori, T. Sakoi, Y. Kurokawa, Effects of seasonal illumination and thermal environments on sleep in elderly men, Building and Environment 88 (2015) 82-88. 